DA. Revista Documentación Administrativa $n^{\circ} 288$, septiembre-diciembre 2010, pp. 161-182 ISSN: 0012-4494

\title{
Notas sobre el Recurso Especial y su finalidad y las funciones del Tribunal Administrativo de Contratos Públicos de Aragón: su doctrina
}

\author{
José María Gimeno Feliu \\ Catedrático de Derecho Administrativo \\ Universidad de Zaragoza \\ gimenof@unizar.es
}

Resumen

Se analiza en este trabajo la organización y principal doctrina del Tribunal administrativo de Contratos Públicos de Aragón. La finalidad es dar cuenta del funcionamiento de este órgano de recursos contractuales y la incidencia en la gestión práctica

\section{Notes of the special review and the functions of the Public Procurement Administrative Court of Aragón: its doctrine}

\begin{abstract}
This paper analyses the organisation and main doctrine of the Public Procurement Review Administrative Court of Aragon. The objective is to explain the functioning of this public procurement review authority and its practical effects.
\end{abstract}

Key words

Public-sector contracts. Public procurement control. Public procurement administrative courts. 


\section{INTRODUCCIÓN ${ }^{1}$}

No parece oportuno en este trabajo dar cuenta del nuevo régimen del recurso especial y sus características, por lo que me detendré en explicar las particularidades de la legislación aragonesa en relación a la misma y las posiciones concretas ya adoptadas $^{2}$.

Como es conocido, Ley 34/2010, de 5 de agosto, de modificación de las Leyes 30/2007, de 30 de octubre, de Contratos del Sector Público, 31/2007, de 30 de octubre, sobre procedimientos de contratación en los sectores del agua, la energía, los transportes y los servicios postales, y 29/1998, de 13 de julio, reguladora de la Jurisdicción Contencioso-Administrativa para adaptación a la normativa comunitaria de las dos primeras, tiene por principal objeto adaptar las referidas leyes a la Directiva 2007/66/CE, del Parlamento Europeo y del Consejo, de 11 de diciembre, por la que se modifican las Directivas 89/665/CEE y 92/13/CEE del Consejo, en lo que respecta a la mejora de la eficacia de los procedimientos de recurso en materia de adjudicación de contratos públicos. Esta norma, por la que se cumple con la STJUE de 3 de abril de 2008, de condena al Reino de España, decide la sustitución del recurso especial del artículo 37 LCSP (en su versión de 2007, ante el mismo órgano) por un nuevo recurso, de carácter potestativo, ante un órgano independiente de carácter administrativo -formados por expertos en derecho administrativo y contratación pública-y que, en el ámbito estatal, recibirá el nombre de Tribunal Administrativo Central de Recursos Contractuales.

A estos Tribunales administrativos se les reconoce facultades, de plena jurisdicción con posible restablecimiento de la situación jurídica individualizada y, en su caso, indemnización, se manifiestan en el contenido de la resolución final.

La novedad es ciertamente relevante tanto desde un plano dogmático como de gestión práctica³. No en vano, como se ha venido recordando, un ordenamiento jurí-

1 Trabajo en el marco del Proyecto MICIN. Ref.: DER 2009-12116. Versión actualizada en junio de 2012.

2 Sobre el recurso y su funcionamiento me remito a mi trabajo Las reformas legales de la Ley 30/2007, de Contratos del Sector Público. Alcance y efectos prácticos, Civitas, Colección Cátedra Derecho Local, Cizur Menor, 2011, pp. 47 a 108. En la doctrina reciente: J.A. Razquin, “El sistema especial de recursos en la contratación pública tras la reforma de la Ley de Contratos del Sector Público”, Revista General Derecho Administrativo núm. 25, 2010; J. A. Moreno Molina, “La Ley 34/2010 y la adaptación en España del Derecho de la Unión Europea en materia de recursos en los procedimientos de adjudicación de contratos públicos", Revista General de Derecho Administrativo núm. 25, 2010; I. Gallego Corcoles, en la Addenda al libro col. Contratación del Sector Público Local, La Ley, $2^{a}$ ed. 2010, pp. XIX a LXX; M. Pulido Quecedo, El nuevo Tribunal Administrativo Central de Recursos contractuales, Aranzadi, 2010, M.A. Bernal Blay, "Aspectos orgánicos del recurso especial en materia de contratación pública en las Comunidades Autónomas", Cuadernos de Derecho Local núm. 26, 2011, pp. 7-26; S. Díez Sastre, La tutela de los licitadores en la adjudicación de contratos públicos, Marciasl Pons, Barcelona, 2012.

3 La opción ha sido, no obstante, cuestionada por S. de la Sierra (“Un legislador impertinente: Derecho de la Unión y procedimiento en la contratación pública”, REDA núm. 149, 2011, pp. 107-1089) o A. Serrano Pascual ("La Ley 3/2011, de 24 de febrero, de medidas en materia de contratación del sector publico de Aragón, o cómo no se debe legislar”, El Consultor de los Ayuntamientos, Rev. 12/2011, 1539), al consi- 
dico que se pretenda efectivo y eficiente en la aplicación de sus previsiones necesita de mecanismos procedimentales y procesales que permitan "reparar y corregir" de forma eficaz las contravenciones a lo dispuesto ${ }^{4}$. De lo contrario se asume un riesgo de corrupción y desconfianza en un sistema que, si bien formalmente puede ser correcto, en la práctica deviene como "generador o facilitador" de incumplimientos que se consolidan y favorecen la idea de que la justicia no es igual para todos los ciudadanos ${ }^{5}$. Es éste un tema crucial, pues del mismo depende la esencia del derecho fundamental a la tutela judicial efectiva

\section{LA REGULACIÓN DEL TRIBUNAL ADMINISTRATIVO DE CONTRATOS PÚBLICOS DE ARAGÓN}

Las Comunidades Autónomas pueden crear su Tribunal ("arrastrando" a las entidades locales y demás poderes adjudicadores de ese ámbito autonómico) 6 . Estos tribunales administrativos tienen también naturaleza administrativa y sus miembros gozarán de inamovilidad e independencia’. La característica principal de la nueva regulación es que se prevé la suspensión de la adjudicación del contrato cuando medie un recurso por alguna de las partes perjudicadas, así como la obligación de anunciar previamente por escrito, al órgano de contratación, la intención de interponer el recurso especial en materia de contratación, en el plazo previsto para la interposición de éste, que se amplía de diez a quince días hábiles, especificándose el inicio del cómputo del plazo en función del acto que se impugne. Para el Estado, desde octubre de 2010, está funcionando el Tribunal Central de Recursos Contractuales.

derar que no se cumple con las reglas de la Directiva 2007/66, al exigir que en nombramiento del presidente sea equivalente al de juez. Opinión que no comparto, por formalista, y entiendo que no hay infracción en tanto la persona reúna las cualidades y estatus propio de la función jurisdiccional. Por el contrario, entiende ajustada ala Directiva 2007/66 esta regulación M.A. Bernal Blay, quien recuerda que el TJUE ya ha aplicado estos parámetros -STJUE de 4 de febrero de 1999, Köllensperger, aparatado 29-admitiendo como válidos órganos administrativos en donde actuara en calidad de Presidente "una persona versada en cuestiones relacionadas con la adjudicación de los contratos públicos"

4 Me remito a mi monografía Novedades de la Ley de Contratos del Sector Público de 30 de octubre de 2007 en la regulación de la adjudicación de los contratos públicos, Civitas, Cizur Menor, 2010, pp. $297-313$.

5 Sobre la necesidad de un sistema de control como elemento para evitar prácticas corruptas me remito a mi trabajo La Ley de Contratos del Sector Público: ¿una herramienta eficaz para garantizar la integridad?. Mecanismos de control de la corrupción en la contratación pública“, REDA 147, 2010, pp 517-535.

6 En el Anteproyecto de Ley de modificación de la LCSP se preveía la posibilidad de creación de órganos independientes para la resolución del recurso especial por parte de las Diputaciones Provinciales, pero esta opción no pasó finalmente al Proyecto de Ley presentado en el Congreso. En consecuencia, parece que se impide que proliferen los tribunales de ámbito municipal -ni siguiera para grandes municipios. Por el contrario, J.A. Moreno Molina defiende que sí existe tal potestad a favor de la Administración local (“Presentación de las últimas reformas de la LCSP y en especial de la Ley 34/2010, de 5 de agosto, de modificación de la LCSP, La Ley de Contratos en los Sectores Especiales y la Ley de la Jurisdicción contencioso administrativa", Revista Contratación Administrativa Práctica, núm. 102, 2010, pp. 25 y 26.

$7 \quad$ Una interesante crónica de los órganos de recursos creados puede verse en M.A. Bernan Blay, “Aspectos orgánicos...", ob. cit., pp. 15 a 25. 
En Aragón, mediante Ley 3/2011, se ha creado crea el Tribunal Administrativo de Contratos Públicos (TACPA), configurado como un órgano colegiado de tres miembros: un Presidente y dos vocales, nombrados entre funcionarios de carrera de cuerpos y escalas del grupo A con la titulación en Derecho, que hayan desempeñado su actividad profesional por tiempo superior a quince (Presidente) y diez (vocales) años en la rama de Derecho Administrativo relacionada directamente con la contratación pública. De entre lo vocales, al menos uno será funcionario de la Administración local. Además, el Secretario/a de la Junta Consultiva de Contratación Administrativa de la Comunidad Autónoma de Aragón ejercerá las funciones de Secretario del Tribunal ${ }^{8}$. Es, por lo demás, y así se declara en la Ley, un órgano independiente, que no recibe ningún tipo de instrucción del Gobierno (y así se desprende del contendido de sus Acuerdos y la valoración de expertos profesionales) ${ }^{9}$. Y es que, a mi entender, y aun siendo un juicio subjetivo, la independencia debe quedar acreditada en el comportamiento y hechos de quienes desempeñan esta función ${ }^{10}$.

Una de las principales característica de la regulación aragonesa es que se prevé que la doctrina del TACPA será de obligado cumplimiento para toda licitación pública (independientemente de que se trate o no de un contrato de importe armonizado, al disponerlo así de forma expresa el artículo 3.1 Ley 3/2011) ${ }^{11}$. Doctrina que se publica en la sede electrónica del TACPA (http://www.aragon.es/OrganosConsultivosGobiernoAragon/OrganosConsultivos/JuntaConsultivaContratacionAdministrativa/AreasTematicas/Tribunal_Administrativo_Contratos_Publicos), le corresponderá conocer y resolver los recursos especiales y cuestiones de nulidad en materia de contratación que se interpongan en el ámbito de los procedimientos de contratación de los poderes adjudicadores incluidos en el ámbito subjetivo de la Ley de Aragón 3/2011: la Administración Pública de la Comunidad Autónoma de Aragón y los Organismos Públicos y demás entidades dependientes o vinculadas a la misma, la Universidad de Zaragoza, las Entidades Locales y sus entes dependientes, así como quienes celebren contratos

8 Destaca la previsión de un régimen transitorio que, hasta que se constituya el Tribunal, atribuye a algunos miembros de la Junta Consultiva de Contratación Administrativa de la Comunidad Autónoma de Aragón que serán designados por el Gobierno de Aragón, el ejercicio de las funciones que le corresponden al Tribunal: José María Gimeno Feliu (Presidente), Asunción Sanmartin Mora (vocal) y Jesús Colas Tenas (Vocal). Actúa como secretaria del Tribunal, en su condición de Secretaria de la Junta Consultiva de Contratación Administrativa de Aragón Ana Isabel Beltrán Gómez. Régimen transitorio que, por motivos evidentes de restricciones presupuestarias, se ha extendido por el nuevo Gobierno autonómico.

9 Opinión contraria a esta independencia, por su actual composición "transitoria" es la mantenida por. A Serrano Pascual, “ La Ley 3/2011...”, ob. cit., p. 1540.

10 Esa independencia funcional del órgano encargado de resolver el recurso respecto del órgano que dictara el acto recurrido fue una reclamación constante de la Doctrina desde un principio. En este sentido en una anterior monografía propuse de lege ferenda a las Juntas Consultivas de Contratación Administrativa Estatal y Autonómicas como los órganos idóneos para conocer de los recursos en materia de contratación pública debido, además de a su independencia, a su especialización por razón de la materia. La nueva contratación pública europea y su incidencia en la legislación española. La necesaria adopción de una nueva Ley de contratos públicos y propuestas de reforma, Civitas, 2006, p. 300.

11 A este Tribunal -constituido el día 11 de marzo de 2011 y con sede en la Plaza de los Sitios $\mathrm{n}^{\circ} 7$ de Zaragoza, $4^{\text {a }}$ planta- se le puede solicitar información en la dirección de correo electrónico tribunalcontra164 nal, de la que se da cuenta en este trabajo. 
subvencionados sujetos a regulación armonizada. Igualmente, resolverá las reclamaciones y cuestiones de nulidad que se interpongan en los procedimientos de adjudicación para la contratación en los sectores del agua, la energía, los transportes y los servicios postales tramitados por todas las entidades públicas descritas en la Ley estatal 31/2007, incluyendo las entidades privadas que gozan de derechos especiales conforme al artículo 3.1 de dicha norma ${ }^{12}$. El objeto del nuevo recurso tiene una doble vertiente. Así, por una lado, se mantiene su restricción a los contratos sujetos a regulación armonizada, incluidos los contratos subvencionados, los contratos de servicios comprendidos en las categorías 17 a 27 del Anexo II de cuantía igual o superior a 193.000 euros, y los contratos de gestión de servicios públicos en los que el presupuesto de gastos de primer establecimiento sea superior a 500.000 euros y el plazo de duración superior a cinco años ${ }^{13}$. Sí que presenta una novedad, en cambio, la relación de actos susceptibles de recurso.

Con el fin de aclarar las reglas de funcionamiento, el TACPA publicó unas guías de funcionamiento, tanto para el recurso especial -de carácter precontractual-, como de la cuestión de nulidad -recurso de carácter contractual- aclarando ya que la comunicación previa era un trámite no esencial que se entendía subsumido con la presentación del recurso y, en todo caso, subsanable. Asimismo, se recuerda por el TACPA que en todo caso, este recurso, de fundamento comunitario, debe interpretarse conforme a la jurisprudencia del TJUE. Así, será también objeto de recurso la decisión de la entidad adjudicadora de cancelar la licitación para la adjudicación de un contrato público (STJUE de 18 de junio de 2002, HI Hospital Ingenieure Krankenhaustechnik PlanungsgesmbH) o el acto por el que la entidad adjudicadora descarta la oferta de un licitador antes incluso de proceder a la selección de la mejor oferta (STJUE de 19 de junio de 2003, GAT). Y lo serán también aquellos modificados que devengan ilegales en tanto sean considerados una nueva adjudicación, tal y como ha interpretado la STJUE de 19 de junio de 2008 (Pressetext Nachrichtenagentur $\mathrm{GMBH})^{14}$ : constituye una nueva adjudicación en el sentido del derecho comunitario de los contratos públicos cuando presentan características sustancialmente diferentes de las del contrato inicial y, por consiguiente, ponen de relieve la voluntad de las partes de volver a negociar los aspectos esenciales del contrato (véase, en este sentido, STJUE de 5 de octubre de 2000, Comisión/Francia, apartados 44 y 46) ${ }^{15}$.

12 Desde este día 11 de marzo de 2011 quedó sin efecto el régimen transitorio previsto en la Disposición Transitoria Segunda de la Ley estatal 34/2010, de 5 de agosto.

13 Con posterioridad, mediante la Ley 3/2012, de "Acompañamiento" a los Presupuestos de la Comunidad Autónoma de Aragón, se ha aprobado el objeto de este recurso especial rebajando los umbrales: 1.000.000 e en obras y 100.000 e en suministro y servicios.

14 La STJUE de 15 de octubre de 2009, Acoset, insiste en esta idea recordando su apartado 62 que "toda modificación sustancial del contrato obligaría a proceder a una licitación". Vid. el Informe de la Junta Consultiva de Contratación Administrativa de Aragón 12/2012, de 23 de mayo, sobre Régimen de publicidad, notificación y formalización de los modificados contractuales en aplicación del artículo 12 bis, Resolución 3/2011, de 24 de febrero, de Medidas en Materia de Contratos del Sector público de Aragón.

15 La STJUE de 13 de enero de 2005 (Comisión/España) entiende -apartado 43- que el precio es un elemento esencial y que, por ello, "una condición de este tipo no puede considerarse una modificación no sustancial de las condiciones originales del contrato”. Máxima en los casos que un incremento elevado viene a quebrar el principio de publicidad y concurrencia -Dictamen Consejo Estado de 21 de octubre de 1992-. 
Por lo demás, resulta de interés la doctrina de la Resolución 5/2011, de 12 de julio, que aclara el funcionamiento y tramitación especial de este nuevo recurso, limitando la posibilidad de ampliar conclusiones por parte del recurrente aplicando las reglas del proceso contencioso (citado por el Tribunal Administrativo Central de Recursos Contractuales en su Resolución 86/2012):

"Por ello, una de sus principales características es que debe ser rápido y eficaz, por lo que debe ser un recurso específico, que impida la celebración del contrato -y, obviamente, el comienzo de su ejecución- hasta que se produce su resolución expresa. Una de las características principales, es que una vez interpuesto el recurso, para dar cumplimiento a la doctrina del Tribunal de Justicia de la UE plasmada en la Sentencia Alcatel, si el acto recurrido es el de adjudicación, quedará en suspenso la tramitación del expediente de contratación (315 LCSP).

Y, en la lógica del sistema, los plazos deberán ser claros evitando incertidumbres al respecto (STJUE de 28 de enero de 2010, Comisión/Irlanda) sin que puedan verse "modulados" discrecionalmente por el ente contratante (STJUE de 28 de enero de 2010, Uniplex), ni tampoco, evidentemente, por los licitadores recurrentes. Plazos que pueden tener carácter preclusivo siempre que sean suficientemente razonables y no limiten desproporcionadamente la acción del licitador (STJUE de 30 de septiembre, Strabag y otros, apartado 37). En todo caso, la información que se facilite a los licitadores debe ser lo suficientemente completa como para permitir que se pueda interponer el recurso por disconformidad con la motivación de la decisión.

La regulación del recurso especial en la LCSP se caracteriza por su "especialidad" en plazos y tramitación. De conformidad con lo establecido en los artículos 312 a 318 LCSP, interpuesto el recurso, el Tribunal lo notificará en el mismo día al órgano de contratación -caso de no haberse depositado el recurso en el registro del órgano de contratación- con remisión de la copia del escrito de interposición y reclamará el expediente de contratación a la entidad, órgano o servicio que lo hubiese tramitado, quien deberá remitirlo dentro de los dos días hábiles siguientes acompañado del correspondiente informe. Dentro de los cinco días hábiles siguientes a la interposición del recurso, dará traslado del mismo a los restantes interesados, concediéndoles un plazo de cinco días hábiles para formular alegaciones, y, de forma simultánea a este trámite, decidirá, en plazo de cinco días hábiles, acerca de las medidas cautelares si se hubiese solicitado la adopción de alguna en el escrito de interposición del recurso o se hubiera procedido a la acumulación prevista en el párrafo tercero del artículo 313.2 LCSP. Los hechos relevantes para la decisión del recurso podrán acreditarse por cualquier medio de prueba admisible en Derecho. Cuando los interesados lo soliciten, o el órgano encargado de la resolución del recurso no tenga por ciertos los hechos alegados por los interesados, o la naturaleza del procedimiento lo exija, podrá acordarse la apertura del período de prueba por plazo de diez días hábiles, a fin de que puedan practicarse cuantas juzgue pertinentes. El procedimiento del recurso especial finaliza con la resolución. El plazo para dictarla es de cinco días hábiles a contar, no desde la interposición, sino desde la recepción de las alegaciones de los interesados o del transcurso del plazo señalado para su formulación y el de prueba en su caso (artículo 317.1 LCSP). Transcurridos estos plazos sin haberse notificado resolución expresa el in- 
teresado podrá considerarlo desestimado a los efectos de interponer recurso contencioso-administrativo. Como se observa, el procedimiento no permite un trámite de "replica" a las alegaciones y los plazos tienen evidente carácter preclusivo, en aras a garantizar los distintos intereses en juego.

Los plazos, coherentemente, son breves, en concreto el plazo de interposición es de quince días hábiles, motivo por el que la notificación de adjudicación debe acomodarse en cuanto a su contenido a lo dispuesto en el artículo 135.4 LCSP. Importa destacar esa referencia al artículo 135.4, pues va a ser el cumplimiento de los trámites allí descritos lo que determinará efectivamente el inicio del plazo para la interposición del recurso contra el acto de adjudicación. En este sentido, debe advertirse que en la reforma de la LCSP operada por Ley 34/2010, de 5 de agosto, de modificación de las Leyes 30/2007, de 30 de octubre, de Contratos del Sector Público, 31/2007, de 30 de octubre, sobre procedimientos de contratación en los sectores del agua, la energía, los transportes y los servicios postales, y 29/1998, de 13 de julio, reguladora de la Jurisdicción Contencioso-Administrativa para adaptación a la normativa comunitaria de las dos primeras, se ha eliminado la posibilidad de que el licitador no adjudicatario pueda solicitar el informe de valoración al que antes se refería el artículo 135.3 LCSP. Para ello, se modifica igualmente el artículo 137 LCSP, en el sentido de suprimir precisamente la posibilidad de solicitar el referido informe. Como contrapartida, se regula en el artículo 135.4 el contenido de la notificación de la adjudicación a los licitadores, que deberá contener, entre otros extremos, “...c) En todo caso, el nombre del adjudicatario, las características y ventajas de la proposición del adjudicatario determinantes de que haya sido seleccionada la oferta de éste con preferencia a las que hayan presentado los restantes licitadores cuyas ofertas hayan sido admitidas". Resulta por tanto que de la actual regulación deriva la obligación de remitir de oficio a los licitadores la información que les permita determinar si ha existido o no una infracción para, eventualmente, plantear un recurso.

El problema que puede plantearse es que la información que contenga la notificación de la adjudicación sea demasiado general, o no pueda individualizarse en relación con algún licitador imposibilitando la eficacia del recurso, circunstancia que ya ha sido denunciada por la Comisión de la UE y aceptada por el Tribunal de Justicia en su Sentencia de 23 de diciembre de 2009 (Asunto C-455/08, Comisión Europea/Irlanda, apartado 32). En tales casos, podría defenderse que el plazo para la interposición del recurso no inicia su cómputo en tanto los licitadores no reciban la información suficiente que les permita, en su caso, fundar el mismo.

Pero no es ese el caso que nos ocupa, tanto porque en la notificación de la adjudicación se ha facilitado a todos los licitadores, además de la trascripción literal de la Orden de adjudicación, copia de la Orden del Consejero de Política Territorial, Justicia e Interior del Gobierno de Aragón, de 31 de mayo de 2011, por la que se clasificaban las ofertas presentadas y seleccionadas y del documento de valoración técnica de las mismas, como por el hecho de que el recurrente no solicito al órgano de contratación-de haberlo considerado necesario para las pretensiones del recurso-acceder al expediente, como es su derecho, antes de la formulación del recurso especial, confundiendo las reglas del proceso contencioso-administrativo con la tramitación especial de este recurso, tras el que no tiene en ningún caso plazo adi- 
cional para formular nuevas alegaciones, en tanto el trámite de audiencia a que se refiere el artículo 316 LCSP es aplicable solo para los otros licitadores partes del procedimiento, pero no para el recurrente, ni tampoco para la Administración cuyo acto se recurre".

Como es conocido, la principal función de los Tribunales Administrativos de contratos públicos es la de control del procedimiento de licitación, pudiendo pronunciarse sobre la anulación de las decisiones ilegales adoptadas durante el procedimiento de adjudicación, incluyendo la supresión de las características técnicas, económicas o financieras discriminatorias contenidas en el anuncio de licitación, anuncio indicativo, pliegos, condiciones reguladoras del contrato o cualquier otro documento relacionado con la licitación o adjudicación, así como, si procede, sobre la retroacción de actuaciones. En todo caso, su función es exclusivamente de control del cumplimiento de los principios y trámites legales, de tal manera que no es posible la sustitución del juicio técnico del que valora los distintos criterios de adjudicación, en tanto se cumplan las formalidades jurídicas, exista motivación y la misma resulta racional y razonable $^{16}$. Por lo demás, este mismo criterio es igualmente defendido por el Tribunal Administrativo Central de Recurso Contractuales en el que se advierte que cuando se tratan cuestiones que se evalúan criterios estrictamente técnicos, el Tribunal no puede corregirlos aplicando criterios jurídicos ${ }^{17}$. En definitiva, corresponde a este Tribunal comprobar si se han seguido los trámites procedimentales y de competencia, respetado los principios de la contratación, y que, no existiendo un error material, la valoración se ajusta a los cánones de la discrecionalidad técnica y existe motivación adecuada y suficiente.

Si de ello deriva que la adjudicación se realice a favor de otro licitador, se concederá al órgano de contratación un plazo un plazo de diez días hábiles para que requiera al licitador seleccionado para que se presente la documentación pertinente para la adjudicación del contrato (art. 47.2 TRLCSP).

\section{LA DOCTRINA DEL TACPA Y SU INCIDENCIA PRÁCTICA}

A este Tribunal Administrativo independiente se le otorgan amplias facultades tanto de anulación como de fijación de indemnizaciones y de multas. Analizaremos a continuación cual ha sido su principal doctrina en relación con cada una de ellas:

a) En lo relativo a las causas de inadmisión, el TACPA ha recordado que una de las especialidades del recurso especial, para garantizar la rápida tramitación de cara al cumplimiento de las prestaciones del contrato objeto de recurso, es que el mismo debe interponerse en el plazo de quince días hábiles y depositarse, o en el Registro del órgano de contratación, o en el del órgano competente para su resolución, de

16 Acuerdo 13/2011, de 14 de julio.

17 Resolución 176/2011, de 29 de junio). 
conformidad con lo exigido por el artículo 44.3 TRLCSP “La presentación del escrito de interposición deberá hacerse necesariamente en el registro del órgano de contratación o en el del órgano competente para la resolución del recurso". La fecha de entrada en cualquiera de ellos determina el cumplimiento de la obligación de presentación en plazo, sin que proceda la aplicación de la previsión del artículo 38.4 c) de la Ley 30/1992, de 26 de noviembre, de Régimen Jurídico de las Administraciones Públicas y del Procedimiento Administrativo Común, respecto de la presentación por los ciudadanos de documentos dirigidos a las Administraciones Públicas en las oficinas de Correos (Acuerdo 12/2011, de 12 de julio). Así, en el Acuerdo 21/2011, de 24 de agosto concluye que "De la documentación presentada, y de la propia afirmación de la recurrente en su escrito de recurso, se constata que con fecha 21 de julio de 2011 le fue notificado el acuerdo de exclusión adoptado por la Mesa de contratación, que el recurso tiene fecha de entrada en el registro del Tribunal el día 10 de agosto de 2011, siendo el dies ad quem el día 8 de agosto, por lo que este recurso es extemporáneo. Cierto es que se presentó en una oficina de correos el día 5 de agosto, pero esa fecha -frente a la regla general de los procedimientos administrativos contenida en el artículo 38.4 c) de la Ley 30/1992, de 26 de noviembre, de Régimen Jurídico de las Administraciones Públicas y del Procedimiento Administrativo Común, que regula la presentación por los ciudadanos de documentos dirigidos a las Administraciones Públicas en las oficinas de Correos- no computa en este procedimiento, de carácter especial, por su propia naturaleza, debiendo estar necesariamente a la fecha de 8 de agosto de 2011". Así, en tanto la entrada en el registro del órgano de contratación o del Tribunal supere el plazo de los quince días, debe declararse la extemporaniedad del recurso. Esto no significa que no pueda interponerse en una oficina de correos (como se afirma en el Acuerdo 3/2011, resulta aplicable el principio "pro actione", y la obligación y la responsabilidad de asegurar el respeto del contenido esencial de ese derecho corresponde, siempre, al Tribunal, como lógica consecuencia de la aplicación de los principios de proporcionalidad y de seguridad jurídica), sino que el plazo a tener en cuenta será el de entrada en el registro especifico, porque el derecho al ejercicio de la acción de recurrir.

b) En la preparación del contrato, la estimación correcta del presupuesto de licitación es fundamental y "debe quedar acreditado en el expediente que el presupuesto de licitación, y por ende el valor estimado, responden a los precios de mercado tal y como exige el artículo 76 LCSP, y aunque como se ha señalado no corresponde entrar en el fondo de la cuestión, es preciso recordar al órgano de contratación que debe velar por la adecuación al mercado del presupuesto de licitación, y que en aquellos supuestos como el que nos ocupa -en el que el coste económico principal de la realización de la prestación es el de la retribución del personal- este coste es el referente económico básico del contrato, que no puede desconocer" "18. Por ello, el Acuerdo 19/2011, de 11 de agosto, considera que procede estimar el recurso en este punto, y debe el Ayuntamiento de Zaragoza acomodar la estructura del presupuesto de

18 Acuerdo 010/2011, de 6 de julio. 
licitación y su desglose -ostes fijos y variables - en términos acordes a la realidad de las magnitudes que los integran ${ }^{19}$. Asimismo, debe darse cumplida aplicación de la previsión del artículo 22 TRLCSP que exige motivar la idoneidad de su objeto, y contenido para satisfacerlas; que deben ser determinadas con precisión, dejando constancia de ello en la documentación preparatoria, antes de iniciar el procedimiento encaminado a su adjudicación. Sólo así, es posible determinar con exactitud el objeto del contrato, y establecer las prescripciones técnicas de forma adecuada y proporcional (Acuerdo 3/2011, de 7 de abril).

c) Cuestión práctica de indudable trascendencia es la relativa a los niveles de solvencia que pueden exigirse en una licitación. Así lo advierte en el Acuerdo 18/2011, de 29 de julio al recordar que la normativa de contratación pública exige para poder contratar con los distintos poderes adjudicadores el cumplimiento previo de los requisitos de capacidad -exigiéndose que el objeto de licitación este comprendido en el objeto social de la empresa licitadora (artículo 57 TRLCSP) - y de solvencia, en sus distintas vertientes económica, técnica y profesional-empresarial, con el objetivo de garantizar la idoneidad del licitador para al ejecución de la prestación demandada. Estos requisitos deben ser proporcionales al objeto del contrato y no debe exigirse una forma jurídica determinada, tal y como ha recordado la Sentencia del TJUE de 18 de diciembre de 2007, Frigerio Luigi. Y destacamos la idea de que "el órgano de contratación, a la hora de tramitar el expediente, debe fijar de forma clara y coherente estos criterios de capacidad, justificando su elección y determinando la forma documental para su concreta acreditación". Estas exigencias de capacidad y solvencia se conforman como un requisito o condición "sine qua nom", cuyo no cumplimiento justifica la exclusión del licitador. Y ello para garantizar el adecuado cumplimiento del interés público que es causa de todo contrato público. De ahí la importancia de su ajustada concreción ya que el carácter desproporcionado de la solvencia que se exija o la no directa vinculación pueden ser un elemento de restricción indebida de la competencia. Así lo ha entendido en su Acuerdo 2/2011, de 6 de abril de 2011, por el que se resuelve el recurso especial, interpuesto por el Colegio Oficial de Arquitectos de Madrid, contra el procedimiento de licitación promovido por el Consorcio Candidatura Juegos Olímpicos Zaragoza-Pirineos 2022, denominado "Servicio de asistencia técnica al Consorcio para la realización de estudios, análisis e Informes técnicos necesarios con la candidatura Zaragoza Pirineos", y que se estima, anulando el pliego, por exigirse unos criterios de solvencia "conjunto de los mismos es desproporcionado, y no guarda directa vinculación al objeto del contrato, y se introduce, de esta forma, un criterio discriminatorio, que tiene un efecto restrictivo de la competencia".

Un caso especial es el relativo a como acreditar esta solvencia, y más en concreto, el compromiso de constituir una futura sociedad titular de la concesión. Es esta la cuestión analizada en Acuerdo 18/2011, de 29 de julio donde se afirma lo siguiente:

19 También el Acuerdo 10/2011, de 6 de julio anulaba la licitación del Ayuntamiento de Teruel por este motivo. 
"El hecho de que esta posibilidad se recoja en el artículo 46. 2 LCSP bajo la rúbrica "Normas especiales de capacidad" no puede suponer dejar de aplicar las reglas generales de capacidad y solvencia contenidas en el Libro I, Título II, capítulo II de la LCSP, en lo que no se opongan a la norma especial. En este sentido es incuestionable, en contra de los que sostiene la recurrente, que la Ley exige, en la lógica del propio contrato de concesión de obra pública y sus especialidades, que los licitadores sean empresas, personas físicas o jurídicas, que cuenten con la habilitación empresarial o profesional exigible a los empresarios que quieran contratar con el sector público, como expresamente exige el artículo 46 LCSP. Por ello no son aplicables en la contratación pública las reglas de capacidad del Código Civil, como pretende la recurrente.

A juicio de este Tribunal el recurrente confunde la posibilidad que la LCSP ofrece de conformar una forma jurídica ad hoc independiente posteriormente a la adjudicación, así como la opción de integración de solvencia con medios externos (ex artículo 52 LCSP), con la obligación de que, en todo caso, se cumplan por quienes pretenden estas fórmulas organizativas las reglas de capacidad y solvencia, pues solo así se garantiza la idoneidad del eventual adjudicatario del contrato y el correcto funcionamiento de la comparación de ofertas para decidir la económicamente más ventajosa.

En cuanto a la adecuación y suficiencia de la solvencia económica y técnica acreditada por la recurrente debe señalarse, en primer lugar, que no existe, ni en la LCSP ni en su normativa de desarrollo, una regulación específica sobre la integración de la solvencia de los empresarios que concurran bajo esta fórmula, como sí sucede en el caso de las Uniones Temporales de Empresarios. Resulta evidente que, como ya se ha señalado, la ausencia de personalidad jurídica de la licitadora determina que quienes contraten realmente sean sus empresarios integrantes, de manera que no solo los requisitos de capacidad de obrar y habilitación empresarial o profesional debe ser directamente exigibles a cada uno de los integrantes, sino también la solvencia y la ausencia de prohibiciones de contratar. Por ello, resultaría adecuada la aplicación analógica del contenido del artículo 24.1 del Reglamento General de la Ley de Contratos de las Administraciones Públicas, aprobado por Real Decreto 1098/2001, de 12 de octubre (en adelante RGLCAP), -que no ha sido derogado expresamente por el Real Decreto 817/2009, de 8 de mayo, de desarroIlo parcial de la LCSP, ni es contrario a sus previsiones- cuando dispone que "en las uniones temporales de empresarios cada uno de los que la componen deberá acreditar su capacidad y solvencia conforme a los artículos 15 a 19 de la Ley y 9 a 16 de este Reglamento, acumulándose a efectos de la determinación de la solvencia de la unión temporal las características acreditadas para cada uno de los integrantes de la misma, sin perjuicio de lo que para la clasificación se establece en el artículo 52 de este Reglamento".

Esta aplicación analógica conlleva, en un supuesto como el que nos ocupa, que cada uno de los integrantes de la futura sociedad concesionaria deban acreditar, además de su capacidad de obrar y habilitación empresarial, la solvencia económica y técnica exigida, aplicándose la regla de acumulación señalada, que en todo caso exige la acreditación por todos y cada uno de ellos de algún tipo de solvencia para que pueda acumularse la misma. 
Hay que señalar en este punto que la legislación vigente no exige un porcentaje mínimo de participación de las empresas en la futura sociedad para proceder a la acumulación de su solvencia, como sí se prevé en las UTES respecto de la acumulación de la clasificación (regla restrictiva que no puede extenderse a otros medios distintos de ésta), por lo que -sin perjuicio de la insatisfacción que la actual regulación en este punto provoca a este Tribunal, al tenerse que admitir en ocasiones solvencias garantizadas por empresarios con un mínimo porcentaje de participación en la figura final- las consideraciones sobre los porcentajes de participación de los integrantes de la futura sociedad".

d) En relación a los denominados trámites formales, se acepta la tesis -marcada tanto por la jurisprudencia como los numerosos dictámenes de la Junta Consultiva de Contratación Administrativa del Estado en la materia-, relativa a la flexibilización de los requisitos formales exigidos en la presentación de la documentación a que se refiere el artículo 146 TRLCSP (Acuerdo 18/2011, de 29 de julio). Asimismo, la eventual confusión entre el clausulado de los Pliegos exige un criterio hermenéutico proclive al principio de igualdad de acceso, de forma que la "oscuridad" de las cláusulas no puede perjudicar a los eventuales licitadores (Acuerdo 5/2011, de 16 de mayo).

En todo caso, como indica el Acuerdo 4/2011, de 12 de abril, las proposiciones de los interesados deben ajustarse a lo previsto en el Pliego de Cláusulas Administrativas Particulares, y su presentación supone la aceptación incondicionada por el empresario de la totalidad de dichas clausulas, sin salvedad o reserva alguna, tal y como dispone el artículo 145 TRLCSP:

"Uno de los aspectos en que la necesidad de adaptación de las proposiciones al contenido de los pliegos es más evidente, es el relativo a la oferta económica, la cual está sujeta a dos requisitos, uno material, puesto que no puede exceder del presupuesto base de licitación, y otro formal, ya que debe atenerse al modelo establecido en los pliegos sin introducir en él variaciones sustanciales. Las proposiciones que no respeten estos requisitos deberán ser rechazadas por la Mesa en resolución motivada, tal y como dispone el artículo 84 del Reglamento General de la Ley de Contratos de las Administraciones Públicas (en adelante RGLCAP).

El límite material, es estricto, y no admite flexibilidad, salvo en aquellos supuestos en que los propios Pliegos hayan permitido variantes y, específicamente, hayan previsto que las mismas podrán superar el presupuesto de licitación (opción de marcado carácter excepcional, en tanto se dificulta el elemento de comparación de ofertas).

El límite formal, sin embargo, no es tan riguroso, y el propio artículo 84 RGLCAP establece que el cambio u omisión de algunas palabras del modelo, con tal que lo uno, o la otra, no alteren su sentido, no será causa bastante para el rechazo de la proposición.

Un excesivo formalismo sería contrario a los principios que deben regir la contratación pública enunciados en el artículo 1 LCSP, la libertad de concurrencia y la 
eficiente utilización de los fondos públicos, exigen que en los procedimientos de adjudicación de los contratos deba tenderse a lograr la mayor concurrencia posible, siempre que los candidatos cumplan los requisitos establecidos".

Esta doctrina no habilita la eventual "relajación" en el procedimiento. Así, en el Acuerdo 23/2011, de 3 de octubre, se declara que son esenciales los actos de apertura de las proposiciones: “Quiere destacarse en este punto la importancia de observar, en la instrucción de un procedimiento complejo como es el de la contratación pública, todos los trámites previstos en la Ley y concretados en el correspondiente PCAP. En concreto, y a los efectos que aquí interesan, debió procederse a la apertura pública del contenido del sobre $n^{\circ} 2$ (cláusula 2.2.6.2 del PCAP) y a dar a conocer el resultado de la valoración del mismo en el acto público de ofertas económicas (cláusula 2.2.6.3. del PCAP). Este trámite, de carácter esencial, tiene por finalidad acreditar el correcto funcionamiento de la Administración en cuanto a la toma de su decisión, y permitir a los licitadores hacer efectivos los derechos que les reconoce la ley".

Esta cuestión es de interés en lo relativo a la forma de las proposiciones. El Acuerdo 16/2011, de 21 de julio nos recuerda que "la cuestión de fondo planteada se refiere a la regla del secreto de las proposiciones que la LCSP y su normativa de desarrollo imponen con el objeto de evitar "manipulaciones" de otros licitadores y garantizar la confiabilidad del sistema. Especial interés tiene el que se desconozcan las ofertas económicas en tanto sean objeto de valoración las proposiciones técnicas, para evitar que pueda influirse en la ponderación del juicio técnico al conocerse previamente la puntuación que obtendría un licitador en estos aspectos reglados o automáticos (de ahí la explicación de la nueva regulación contenida en el artículo 134.2 LCSP).

Es esta, por lo demás, una práctica derivada del derecho a una buena administración que explica la exclusión del licitador que la incumple, y por la que debe exigirse la debida diligencia a los licitadores al presentar y documentar sus ofertas, en aras a preservar la finalidad del procedimiento y los principios de igualdad de trato que lo inspiran.

Dicho esto, conviene determinar para el caso concreto objeto de recurso, si la oferta de la empresa recurrente había incumplido este requisito esencial -como advierte la Mesa de contratación-, para lo que es necesario realizar una interpretación finalista y sistemática, que obliga al órgano gestor a acreditar de forma racional el incumplimiento del licitador de este deber de no desvelar la oferta económica de forma anticipada. Y no son suficientes meras suposiciones o juicios de valor técnico que no permitan constatar de forma fehaciente este incumplimiento, pues lo contrario, cuando menos, quebraría el principio de proporcionalidad y conllevaría una contravención del principio de igualdad de trato y, además, en tanto restrictiva de la concurrencia, el de eficiencia".

e) Cuestión de interés práctico resulta la relativa a la interpretación del artículo 151.2 TRLCSP, que establece un plazo máximo de 10 días para presentar la documentación antes de la formalización del contrato, entendiendo que de no cumplirse 
el licitador retira su oferta. En el Acuerdo 8/2011 el TACPA declara que la valoración de la documentación requerida, y los efectos que se derivan de su no presentación o presentación inadecuada, debe realizarse atendiendo a los distintos principios jurídicos en juego y, en especial, el de proporcionalidad, con el efecto de no convertirlo en un trámite de "exclusión" 20 . La redacción de este precepto ha suscitado ciertas dudas interpretativas. Una primera relativa al carácter preclusivo del plazo y su eventual prorroga. Así, el Tribunal Administrativo Central de Recursos Contractuales en su Resolución n 153/2011, de 1 de junio, había manifestado que el plazo de diez días hábiles, establecido en art. 151.2 TRLCSP, para la aportación de los documentos por parte del empresario propuesto adjudicatario no puede ser rebasado. Concretamente afirma,

\begin{abstract}
“A estos efectos interesa destacar que el plazo de diez días hábiles, que establece el artículo 135.2 antes reproducido, para aportar la justificación exigida no puede ser rebasado, señalando, además, el pliego de cláusulas expresamente en la cláusula IX, apartado 5 que dicho plazo es "máximo", pues de no ser así ello supondría un punto de máxima inseguridad jurídica para el resto de los licitadores, y sería contrario a los principios de publicidad, libre concurrencia y transparencia en la contratación, consagrados en los artículos 1 y 123 de la Ley de Contratos del Sector Público."
\end{abstract}

Esta cuestión se suscita para el TACPA que precisa la interpretación del artículo 151.2 TRLCSP aceptando que la consideración de la preclusividad de los plazos procesales establecidos en la LCSP debe hacerse una clara distinción entre aquellos plazos procesales que establecen el tiempo para una actuación simultánea de todos los licitadores y aquellos plazos que en la LCSP delimitan una actuación específica y concreta de un licitador concreto. En el primer supuesto, al exigir el cumplimiento del plazo sin posibilidad alguna de ser modificado a solicitud de uno de los obligados, se garantiza la igualdad de trato y de comportamiento de todos ellos: el supuesto más emblemático seria el plazo para la presentación de las proposiciones.

De forma distinta, en el supuesto de un plazo otorgado específicamente a un licitador para el cumplimiento de una actuación para cuya materialización quizás ha de

20 Por ello, a la vista de la documentación presentada tras el requerimiento efectuado, el TACPA constata que dentro de los plazos concedidos el licitador cumplimentó en tiempo lo solicitado, de lo que se deduce -al menos inicialmente- que su voluntad no era la de retirar su proposición, sino todo lo contrario. La cuestión objeto de controversia radica en si la documentación acreditativa permite dar por cumplida la exigencia de capacidad funcional de los trabajadores para el concreto puesto de trabajo, emitiendo el órgano de contratación un juicio negativo que no motiva ni justifica suficientemente, realizando únicamente un juicio de valor técnico para el que carece de competencia específica. Desde la lógica del sistema previsto, atendiendo a la voluntad inequívoca del licitador de ejecutar el contrato adjudicado, y a las consecuencias jurídicas derivadas de la aplicación estricta de este trámite -con los efectos de una exclusión de la licitación, eventual incautación de una garantía provisional, tramitación de expediente de prohibición de contratar y perjuicio al interés público, desde la perspectiva de la oferta económicamente mas ventajosaesta duda sobre la adecuación de la documentación presentada exigiría cuando menos se hubiese solicita-

174 do aclaración al IASS, Organismo Autónomo de la misma Administración y que emitió los informes presentados, sin que ello implique trasladar la carga documental del licitador a la Administración contratante. 
acudir a la realización de trámites ante Organismos externos a su estructura empresarial o que debe realizar actuaciones cuyo resultado no depende en exclusiva de su voluntad, y la ampliación del plazo no perjudica derechos de igualdad de trato de los licitadores puesto que solo el licitador afectado está compelido a realizar una determinada actuación en un momento procesal en que la ampliación del plazo no lesionaría derechos de los licitadores.

Pueden darse algunos ejemplos para clarificar la posición que se defiende. Todos los licitadores deben entregar su proposición en un plazo determinado. Este plazo es preclusivo porque cualquier ampliación del plazo otorgada a un licitador supondría un trato diferente con respecto a otros que habrían tenido menos tiempo para preparar la oferta. En idéntico sentido el plazo para la interposición del recurso especial establecido en art. 44.2 TRLCSP. El plazo de 10 días hábiles del art. 155.2 TRLCSP entendemos que es ampliable si concurren causas que justifiquen dicha ampliación porque su concesión nada perjudica a los derechos del resto de licitadores, que formularon sus ofertas y ya fueron valoradas y que posteriormente tendrán derecho a recurrir si lo consideran necesario. También el plazo de cinco días para la formalización del contrato armonizado, transcurrido el plazo de quince días hábiles para la interposición del recurso especial sin que se haya interpuesto éste, entendemos que también es un plazo que, si concurre una causa que lo justifique, el órgano de contratación puede autorizar su ampliación. Asimismo, el plazo de quince días hábiles para la formalización del contrato no armonizado contados a partir de la fecha de la notificación de la adjudicación en el supuesto de una UTE puede ser insuficiente para la constitución en escritura pública de la UTE, obtención del NIF, etc. En esos supuestos, no debe descartarse la aplicación de la previsión del art. 49 de la ley 30/1992, de 26 de noviembre, de Régimen jurídico de las Administraciones Públicas y del Procedimiento Administrativo Común que establece en su apartado 1 que respecto los plazos, siempre que éstos no hayan vencido, "La Administración, salvo precepto en contrario, podrá conceder de oficio o a petición de los interesados, una ampliación de los plazos establecidos, que no exceda de la mitad de los mismos, si las circunstancias lo aconsejan y con ello no se perjudican derechos de tercero. El acuerdo de ampliación deberá ser notificado a los interesados"21.

Una segunda es la relativa a la cumplimentación del trámite por parte del licitador propuesto como adjudicatario. En este punto el TACPA declara que: “El artículo 135.2 impone al licitador que ha presentado la oferta económicamente más ventajosa la carga de aportar una documentación determinada en el plazo establecido. La consecuencia de no atender el requerimiento en plazo, es que el órgano de contratación entenderá que el licitador ha retirado su oferta y por tanto quedará excluido de la licitación, además procederá la incautación de la garantía provisional si se hubiera exigido su constitución (artículo 91.4 LCSP) y la incoación de un expediente de declaración de prohibición de contratar (artículo 49.2 d LCSP). Dados los graves efectos

21 Resolución n 153/2011, de 1 de junio, del Tribunal Administrativo Central de Recursos Contractuales 
negativos que tiene para el licitador el incumplimiento del plazo, tienen especial importancia las cuestiones procedimentales". Por ello, este acto, tal y como ha declarado el Tribunal Administrativo de Contratos Públicos de Aragón en el Acuerdo 8/2011, de 27 de junio de 2011, tiene que ser motivado y notificado debidamente y merece la calificación de acto de tramite cualificado a efectos de recurso ${ }^{22}$.

f) De especial intereses la doctrina sobre la valoración de las proposiciones. En el Acuerdo 23/2011 de 3 de octubre se indica que "La discrecionalidad técnica no puede servir, amparar, ni ocultar, una contratación directa en clara vulneración de los principios de concurrencia y eficiencia en la gestión de los fondos públicos, amén de resultar ajena a lo que es una actuación conforme al derecho a una buena administración”. En todo caso, como señala este Acuerdo, la falta de la debida y explicitada ponderación de los criterios de adjudicación del procedimiento, indicados en el pliego, y exigida por el artículo 150 TRLCSP, es una infracción grave -calificable como vicio de nulidad de pleno derecho- que afecta a los fines mismos del ordenamiento jurídico de la contratación pública, explicitados en el artículo 1 TRLCSP, el de garantizar los principios de "publicidad y transparencia de los procedimientos y no discriminación e igualdad de trato de los candidatos". En el mismo sentido, el artículo 123 LCSP, al referirse de modo concreto a los procedimientos de adjudicación, dispone que "los órganos de contratación darán a los licitadores y candidatos un tratamiento igualitario y no discriminatorio y ajustarán su actuación al principio de transparencia".

Así lo había ya afirmado el TACPA en su Acuerdo 3/2011, de 7 de abril:

“La valoración de los criterios objetivos de adjudicación, contenida en el expediente del contrato de suministro, del material necesario para la realización de técnicas analíticas automáticas de hematimetría, para el servicio de Hematología del Hospital de Alcañiz, no puede ser admitida, porque la falta de la debida y explicitada ponderación de los criterios de adjudicación del procedimiento, indicados en el pliego, y exigida por el artículo 134 LCSP, es una infracción grave que afecta a los fines mismos del ordenamiento jurídico de la contratación pública, explicitados en el artículo 1 LCSP, el de garantizar los principios de "publicidad y transparencia de los procedimientos y no discriminación e igualdad de trato de los candidatos". En el mismo sentido, el artículo 123 LCSP, al referirse de modo concreto a los procedimientos de adjudicación, dispone que "los órganos de contratación darán a los licitadores y candidatos un tratamiento igualitario y no discriminatorio y ajustarán su actuación al principio de transparencia"."

En estos importantes Acuerdos se insiste en que el principio de igualdad de trato implica, concretamente, que todos los licitadores potenciales deben conocer las reglas del juego, y éstas se deben aplicar a todos de la misma manera. En concreto, los

22 En el supuesto concreto se estima el recurso por entender que no se había cumplimentado adecuadamente el requerimiento en el plazo concedido a la UTE integrada por las mencionadas mercantiles, clasificada en primer lugar, en el sentido de entender cumplimentadas adecuadamente las exigencias requeridas en el artículo 135.2 LCSP, por lo que procedía la adjudicación del contrato. 
artículos 116 y 117 TRLCSP regulan los Pliegos de prescripciones técnicas y las reglas para su establecimiento, señalando -en coherencia con el contenido del mencionado artículo 1 LCSP- que las prescripciones técnicas deberán permitir el acceso en condiciones de igualdad de los licitadores, sin que puedan tener por efecto la creación de obstáculos injustificados a la competencia.

Esta última declaración impone la necesidad de que, al definir el objeto del contrato, los órganos de contratación tengan especial cuidado de no hacerlo mediante la mención de características técnicas de la prestación que excluya a todas las demás capaces de cumplir la misma función. $Y$ esto justamente es lo que concreta el apartado 8 del artículo 117 TRLCSP, al establecer una serie de métodos a través de los cuales no está permitido especificar las características de la prestación, salvo que se cumpla el doble requisito de que no se pueda hacer una descripción lo bastante precisa e inteligible y se añada la expresión "o equivalente", mediante la cual no se pretende otra cosa sino permitir la presentación de ofertas relativas a prestaciones que puedan cumplir la misma función que aquella cuyas características se han utilizado en el pliego para definir la prestación.

g) La falta de motivación de la adjudicación de los contratos, o en su notificación a los licitadores, ha sido una de las causas de impugnación mas reiteradas en la actuación del TACPA. Así, desde su Acuerdo 3/2011, de 7 de abril, en el que se señala:

«En cuanto a la necesidad de motivación de la adjudicación, y en consecuencia la de su notificación, la jurisprudencia de nuestro Tribunal Supremo ha venido reiterando que la motivación de la decisión de adjudicación de un contrato, constituye un elemento esencial para evitar la arbitrariedad, al tiempo que permite a los demás interesados conocer los argumentos utilizados por el órgano de contratación que permita, en su caso, impugnar la adjudicación.

No obstante, aun cuando la motivación no venga reflejada en el acto administrativo que ponga fin al procedimiento, se daría cumplimiento a la exigencia de los artículos 54.2 y 58 de la LRJPAC, siempre que la misma apareciere suficientemente justificada a lo largo del procedimiento.

La Ley 34/2010, de 5 de agosto, modificó la LCSP, transponiendo a nuestro ordenamiento jurídico la Directiva 2007/66/CE, del Parlamento Europeo y del Consejo, de 11 de diciembre, que, a su vez, modificó las Directivas 89/665/CEE y 92/13/ CEE del Consejo, dando una nueva redacción al artículo 135, en cuanto a la notificación de la adjudicación, que debe realizarse a los licitadores, siendo la finalidad de dicha modificación que se comunique, con suficiente detalle, cuál es el resultado de la licitación, y las razones que han llevado al órgano de contratación a adoptar una decisión en tal sentido, tal y como recoge expresamente el Preámbulo de la Ley.

La Orden de la Gerencia del Sector de Alcañiz, del Departamento de Salud y Consumo del Gobierno de Aragón, por la que se adjudicó el contrato de suministro, del material necesario para la realización de técnicas analíticas automáticas de he- 
matimetría para el servicio de Hematología del Hospital de Alcañiz, carece de motivación. Y en la documentación, del expediente remitido, tampoco aparece suficientemente justificada la misma.

La motivación que se contiene en los informes técnicos del expediente, como bien afirma el Informe 1/2011, de 12 de enero, de la Junta Consultiva de Contratación Administrativa de la Comunidad Autónoma de Aragón, no se ajusta a las exigencias legales de dicha obligación, y nada tiene que ver con el margen de discrecionalidad, del que gozan los poderes adjudicadores, para la fijación de los criterios de adjudicación.

La STS de 13 de julio de 1984 discurría, sobre este particular, indicando que «lo discrecional se halla o debe hallarse cubierto por motivaciones suficientes, discutibles o no, pero considerables en todo caso, mientras que lo arbitrario, o no tiene motivación respetable sino pura y simplemente la conocida como "sit pro ratione voluntas", o la que ofrece lo es tal que escudriñando en su entraña, denota, a poco esfuerzo de contrastacion su carácter realmente indefendible y su inautenticidad. Por ello el primer criterio de deslinde entre lo discrecional y lo arbitrario es la motivación, porque si no hay motivación que la sostenga el único apoyo de la decisión será la voluntad de quien la adopte».

Al más reciente Acuerdo 6/2012, de 31 de enero, en el que se declara:

“En este sentido, la notificación de la Resolución de la Dirección Gerencia del Servicio Aragonés de Salud de 20 de diciembre de 2011, por la que se adjudicó el contrato, no hace referencia a todos los elementos determinantes de la resolución dictada. Es cierto que en la documentación del expediente remitido se encuentra el informe técnico de valoración de las ofertas emitido el 30 de noviembre de 2011, con un contenido exhaustivo que examina cada una de las propuestas técnicas, las compara y les asigna una puntuación. Sin embargo, su contenido no ha sido trasladado a los lidiadores, por lo que implica falta de motivación de la notificación, lo que se traduce en indefensión al carecer de la información suficiente para poder presentar un recurso.

La motivación que se contiene en la notificación de la adjudicación de 20 de diciembre de 2011 no se ajusta así a las exigencias legales de dicha obligación, y nada tiene que ver con el margen de discrecionalidad, del que gozan los poderes adjudicadores, para la fijación de los criterios de adjudicación. Como bien afirma el Informe 1/2011, de 12 de enero, de la Junta Consultiva de Contratación Administrativa de la Comunidad Autónoma de Aragón: «En la aplicación de los criterios de adjudicación de los contratos que dependen de un juicio de valor, la ponderación en términos numéricos de las propuestas, sin detallar un resumen de los motivos concretos por los que se asigna cada puntuación, es inadmisible por carecer de motivación. Una valoración de los criterios objetivos de adjudicación sin expresión de las razones por las que se llega a ella no puede ser admitida por resultar imposible de revisar, pudiendo incurrir en causa de anulación por falta de la debida y explicitada ponderación de los criterios de adjudicación del procedimiento indicados en el plie178 go, exigida por el artículo 134 LCSP». 
No desvirtúa esta conclusión el hecho de que en acto público «la valoración fue informada a los licitadores", ya que éste trámite del procedimiento -recogido en el artículo 134.2 LCSP, y concretado en la cláusula 2.2.6.3 del PCAP- tiene por finalidad última preservar la imparcialidad y objetividad a la hora de valorar los criterios sometidos a evaluación previa de la oferta, pero en ningún caso puede sustituir al contenido necesario de fa notificación de la adjudicación».

h) Interesa destacar la doctrina del Acuerdo 29/2011, de 15 de diciembre, por el que se resuelve el recurso especial, interpuesto por UNIPOST, S.A., en relación al Acuerdo marco de contratación centralizada de los servicios postales y telegráficos para la Administración de la Comunidad Autónoma de Aragón, sus Organismos Autónomos y restantes Entes públicos autonómicos y locales adheridos», donde se decide la anulación del mismo por cuanto su operatividad práctica comporta un cierre del mercado postal:

«En primer lugar, la recurrente considera que este acuerdo marco implica una restricción de la competencia, al cerrar el mercado postal durante un plazo de cuatro años. Como es sabido, los acuerdos marco -conviene recordar que era una posibilidad que se contenía ya en la Ley $48 / 1998$, de 30 de diciembre, sobre procedimientos de contratación en los sectores del agua, la energía, los transportes y las telecomunicaciones, por la que se incorporan al ordenamiento jurídico español las Directivas 93/38/CEE y 92/13/CEE- se regulan en los artículos 180 a 182 LCSP. Mediante este nuevo procedimiento, abierto a todo tipo de contrato, los sujetos contratantes podrán celebrar acuerdos marco, cuya duración no podrá superar los cuatro años, salvo en casos excepcionales, debidamente justificados, en particular por el objeto del acuerdo marco. A través de este procedimiento «precontractual» los poderes adjudicadores cuentan con la posibilidad de celebrar un acuerdo marco con uno o varios operadores económicos, y de organizar, en este último supuesto, posteriores «mini licitaciones», abiertas a ia participación de las partes en el acuerdo marco, a medida que se vayan haciendo patentes las necesidades del poder adjudicador.

Esta técnica de racionalización administrativa aporta simplificación, eficiencia y normalización, como bien advierte el Informe de la unidad gestora. Pero encuentra un límite infranqueable, que consiste en que no puede utilizarse de manera abusiva, o de manera que la competencia se vea obstaculizada, restringida o falseada. Así se establece en el artículo 180. I. LCSP, cuando determina: «Los órganos de contratación del sector público podrán concluir acuerdos marco con uno o varios empresarios con el fin de fijar las condiciones a que habrán de ajustarse los contratos que pretendan adjudicar durante un periodo determinado, siempre que el recurso a estos instrumentos no se efecfúe de forma abusiva o de modo que la competencia se vea obstaculizada, restringida o falseada».

Es decir, junto a la lógica del principio de la eficacia y eficiencia pretendido por la entidad contratante en la justificación de este tipo de procedimiento, juega también, como otro principio a proteger el que no haya efectos restrictivos sobre la competencia. 
Y aquí radica el núcleo de la pretensión del recurrente, que exige determinar si el concreto diseño práctico de este acuerdo marco puede merecer el juicio de que es restrictivo de la competencia. Un dato importante es que se trata de un acuerdo marco con un único proveedor, lo que de por sí implica una limitación, que bien podría tener su justificación en la correcta prestación del contrato. Pero el ámbito de este acuerdo, claramente excepcional por su amplitud desde la perspectiva subjetiva, que engloba la casi totalidad de las entidades públicas de Aragón (Gobierno de Aragón, Diputaciones Provinciales, Comarcas, Mancomunidades y principales municipios), que necesariamente recaerá en un único prestador del servicio, supone un cierre del mercado público de los servicios postales en Aragón durante un plazo de cuatro años, lo que resulta contrarío al principio de libre competencia.

Esta afirmación se encuentra avalada por el hecho de que el sector postal es un mercado recientemente liberalizado -Ley 43/2010, de 30 de diciembre, del servicio postal universal, de los derechos de los usuarios y del mercado postal, por la que se transpone la Directiva 2008/6/CE (en adelante Ley 43/2010), que declara que los servicios postales son servicios de interés económico general que se prestan en régimen de libre competencia- donde ha existido un operador dominante, que cuenta ya con los medios personales y materiales como consecuencia de dicha posición inicialmente monopolista, por lo que un acuerdo marco como el recurrido, por dicha dimensión, impide el principio recogido en la reciente legislación postal, quebrando en la práctica sus principios regulatorios. A este efecto restrictivo de la competencia conduce también el hecho de que no se hayan previsto lotes, lo que facilitaría un mayor número de ofertas y más ajustadas técnica y económicamente, y que la valoración como criterio de adjudicación de mayores medios personales y materiales, en un contrato de tal dimensión, beneficia claramente al lidiador que originalmente ha mantenido una posición de operador dominante del mercado, lo que dificulta, cuando menos, que el principio de apertura de los servicios postales sea realmente efectivo».

i) Por último, como es sabido, al TACPA se le reconoce la potestad de imponer sanciones si se aprecia temeridad o mala fe en la interposición del recurso o en la solicitud de medidas cautelares: entre 1.000 y 15.000 euros, que se fijará en función de la mala fe apreciada y el perjuicio ocasionado al órgano de contratación y a los restantes licitadores (art. 47.5 TRLCSP). Por Acuerdo 11/2011, de 7 de julio 2011, del Tribunal Administrativo de Contratos Públicos de Aragón se ha impuesto aun licitador multa de 1000€: “... de forma indebida, ha ocultado ese dato en la justificación del recurso, acompañando como única documentación un segundo fax, conociendo de la existencia del primero, pretendiendo así ocultar su clara falta de diligencia en la organización empresarial. Esta pretensión, amén del reproche que desde una ética empresarial merece, implica una clara deslealtad y abuso del principio de buena fe, exigible a todas las partes en un procedimiento de licitación, por lo que este Tribunal aprecia una evidente mala fe en la interposición del recurso, acordando por ello, en atención a lo dispuesto en el artículo 47.5 TRLCSP, la imposición de una multa a la recurrente de 1.000 euros, por cuanto se entiende que hay una clara intención de confundir al Tribunal con los datos aportados, produciendo retrasos en la tramitación del contrato con 180 los correspondientes perjuicios a la entidad licitadora" 
Una importante doctrina es la relativa a la impugnación indirecta del pliego tras la adjudicación. Así en el Acuerdo 14/2011, de 19 de julio, se acepta la tesis de que una vez aceptado y consentido el Pliego -ley por la que se rige el procedimiento licitatorio- el mismo deviene firme, y no cabe ya cuestionar ninguno de sus extremos, conforme a la jurisprudencia consolidada por el Tribunal Supremo, siempre que no se aprecien vicios determinantes de nulidad de pleno derecho.

Este es, igualmente, el criterio del Tribunal Administrativo Central de Recursos Contractuales en la resolución dictada el 20 de julio de 2011, por la que se resolvía el recurso 155/2011 y, mas recientemente, en la de 21 de marzo de 2012, por la que se resuelve el recurso 44/2011. En consecuencia, ante un vicio de nulidad si es posible la anulación de uno de los criterios contenidos en el pliego. Esta es la tesis sostenida en Acuerdo 20/2012, por entender que existe una manifiesta quiebra del principio de igualdad -ya que los criterios de adjudicación reflejados en el pliego no expresan adecuadamente los requisitos y límites exigibles- que pueden generar, como así ha sucedido, una aplicación discriminatoria de lo que se infiere, por sí solo, el vicio de nulidad absoluta ${ }^{23}$.

\section{A MODO DE CAPITULACIÓN: RETOS PENDIENTES}

Sin duda, la creación y puesta en funcionamiento ha supuesto un notable avance en la necesidad de un efectivo control que, además de garantizar el derecho a la tutela, permita una gestión más eficiente de los fondos públicos. La actividad desplegada por el TACPA durante su primer año supone un control sobre el 25 por ciento de los contratos SARA celebrados en Aragón hasta la fecha, con un porcentaje de estimación del recursos en un cincuenta por ciento. El cumplimiento estricto de los plazos, la publicidad de los Acuerdos y su fundamentación han dotado de credibilidad el sistema aunque existen ciertas sombras. Una derivada del carácter "transitorio" del nombramiento de sus miembros, donde las necesidades presupuestarias prevalecen y obligan a prolongar esta situación. En todo caso, aun con ese carácter, en nada se

23 La STJUE de 4 de diciembre de 2003, as. C-448/01, EVN AG, se refiere a la hipótesis de que la anulación de un criterio de adjudicación de forma previa a la adjudicación del contrato. La duda que se plantea es si en estos supuestos procede adjudicar el contrato — haciendo abstracción del criterio anulado- o por el contrario, es preciso convocar una nueva licitación. Pues bien, el Tribunal concluye que sólo la segunda de las alternativas se ajusta al Derecho Europeo. Y es que:

"[...] los principios de igualdad de trato y de transparencia de los procedimientos de adjudicación implican que las entidades adjudicadoras deben atenerse a la misma interpretación de los criterios de adjudicación a lo largo de todo el procedimiento (véase, en este sentido, en particular, la sentencia SIAC Construction, antes citada, apartado 43). Por lo que atañe a los propios criterios de adjudicación, hay que admitir con mayor razón que no deben ser objeto de ninguna modificación a lo largo del procedimiento de adjudicación. De ello se deduce que, en el caso de que el órgano que conoce del recurso anule una decisión relativa a algún criterio de adjudicación, la entidad adjudicadora no puede continuar válidamente el procedimiento de adjudicación haciendo abstracción de dicho criterio, puesto que ello equivaldría a modificar los criterios aplicables al procedimiento en cuestión».

En definitiva, la anulación de un criterio de adjudicación por parte del órgano de recurso debe conducir, inexorablemente, a la convocatoria de un nuevo procedimiento de licitación. 
ha resentido la necesaria independencia. Una segunda, es el escaso conocimiento por los licitadores de esta posibilidad de recurso, que deriva, quizá, de la no visualización pública de este nuevo mecanismos de recurso y sus especiales características ${ }^{24}$.

Un problema práctico, derivado de la importación del modelo de las Cortes Generales, es que para las Cortes de Aragón, Cámara de Cuentas y Justicia de Aragón, la Ley $3 / 2011$, prevé o que puedan crear un órgano de control equivalente que cumpla los requerimientos legales: independencia y capacitación en la materia de sus miembros, o que se celebre convenio con el Gobierno de Aragón para residenciar los eventuales recursos -que se estiman muy escasos- ante el Tribunal Administrativo de Contratos Públicos de Aragón. Hasta la fecha, estas Instituciones no han optado por ninguna de las soluciones descritas lo que plantea dos problemas: uno primero, derivado de la previsión de la Ley 34/2010, es que quedan obligadas por la Disposición Transitoria Segunda de la Ley 34/2010, resolviendo el recurso el órgano de contratación con las reglas ahora vigentes, pero con la "penalización" que consiste en la suspensión automática hasta que la levante el Juez si no hay estimación del recurso especial. Una segunda, de carácter más político-institucional, es que se esta incumpliendo un mandato legal, de origen comunitario, que amén de un eventual procedimiento de inspección por la UE, puede mermar la credibilidad de unas Instituciones que por su propia función -dos de ellas de control- deben ser las primeras en dar cumplimiento efectivo a las normas.

Y desde una perspectiva de eficacia y eficiencia, parece oportuno aconsejar la opción del convenio con el Tribunal Administrativo de Contratos Públicos de Aragón, en tanto órgano independiente, que no controla el Gobierno, sin que ante un recurso ante este órgano se mermen las competencias de las Instituciones referidas, al estar en presencia de un prototipo de acto materialmente administrativo, claramente diferenciado de sus funciones específicas, sin que por ello pueda entenderse un control o tutela a su autonomía.

24 Se encuentra en tramitación por su aprobación el Reglamento de Funcionamiento del Tribunal Administrativo de Contratos Públicos de Aragón y de los Procedimientos de revisión en materia de contratación del sector público de su competencia. 